
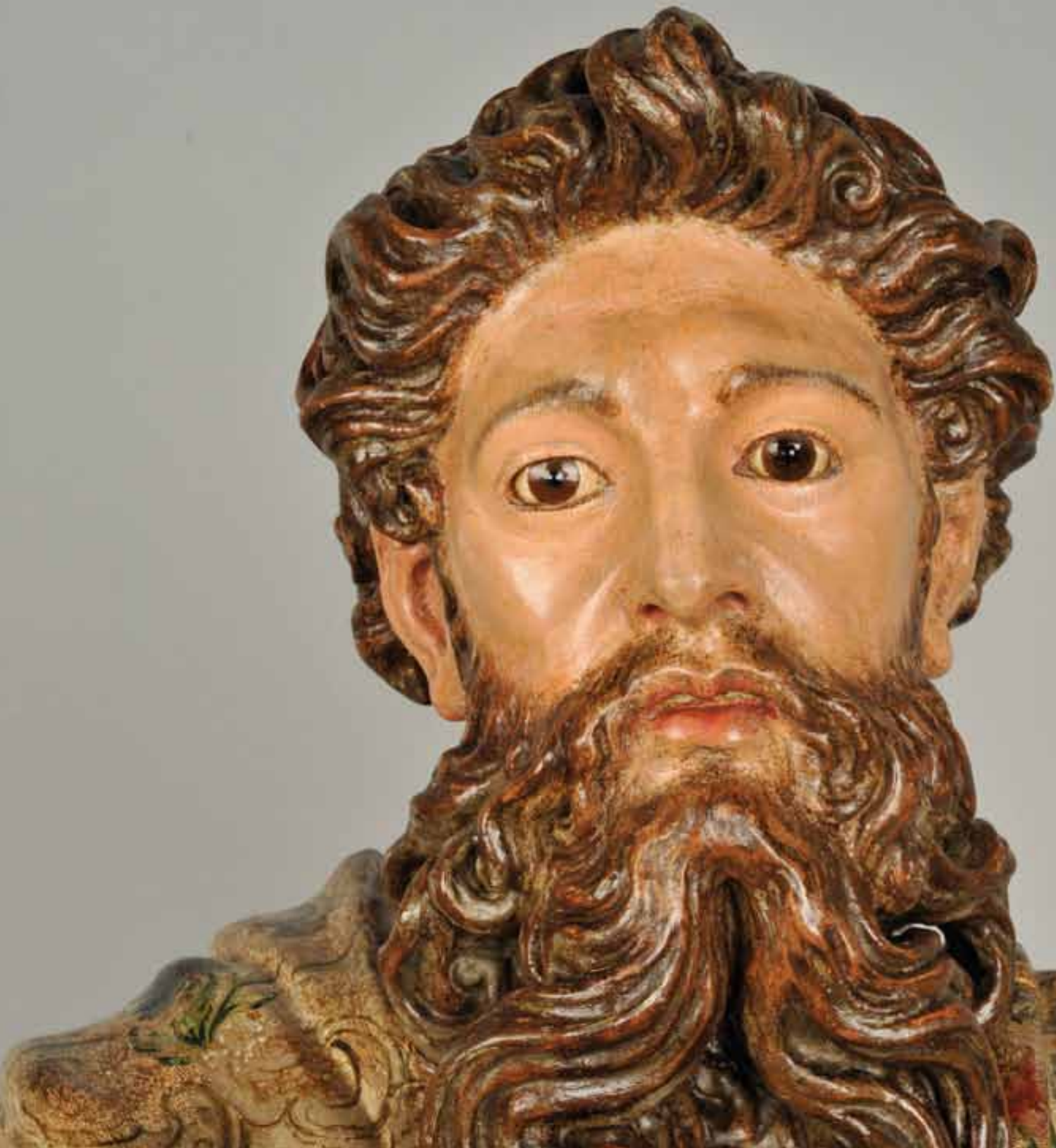


\section{La revisión documental en el estudio histórico artístico: la nueva atribución del patrón de Écija}

Jesús Porres Benavides, restaurador, Taller de Escultura, Centro de Intervención del IAPH; Carmen Garcia Rosell, historiadora del arte, Departamento de Investigación, Centro de Intervención del IAPH

\section{Resumen}

La imagen de San Pablo que nos ocupa, restaurada en los talleres del IAPH, se realizó en 1575 por encargo del Cabildo para que fuera su imagen titular. Aunque tradicionalmente se ha venido considerando como obra salida de la gubia del desconocido escultor local Salvador Gómez de Navajas, un análisis estilistico detenido sobre la imagen y una revisión bibliográfica y documental realizada por los investigadores astigitanos Gerardo García y Jesús Porres han inclinado a considerarla como obra del escultor castellano Juan Bautista Vázquez, El Viejo, y de su discipulo Gaspar del Águila. Durante su restauración, y con la investigación documental y bibliográfica, hemos podido dar como segura esa atribución y comprobar los cambios que la imagen ha sufrido a lo largo de su historia material que han podido contribuir a mantener durante tanto tiempo la errónea atribución del Patrón al escultor local astigitano.

Aunque a veces creemos los historiadores contemporáneos que sobre algunas figuras artisticas y bienes culturales esté ya todo dicho y fundamentado, la revisión de la historiografía y de la documentación, junto al análisis de la obra de arte, produce, como en el caso de la escultura que nos ocupa, agradables sorpresas que permiten atribuir correctamente algunas imágenes que tradicionalmente se mantenian en el acervo artistico de unos autores que no le correspondian.

\section{Palabras clave}

Águila, Gaspar del / Atribución / Centro de Intervención / Écija (Sevilla) / Esculturas de bulto redondo / Esculturas policromadas / Historia / Instituto Andaluz del Patrimonio Histórico / Intervención / Investigación / Patrimonio mueble / Vázquez, Juan Bautista, Ilamado el Viejo / San Pablo Apóstol / 1574 


\section{SAN PABLO Y ÉCIJA}

Nos encontramos ante una representación iconográfica del Apóstol de los gentiles, San Pablo, patrón canónico de Écija desde 1642 por bula papal de Urbano VIII. La vinculación de la ciudad astigitana con la figura del Apóstol viene determinada por dos hechos fundamentales: por un lado, la creencia tradicional de la visita del Santo a la ciudad en su viaje a la Peninsula Ibérica y, por otro, el milagro que el mismo produjo en la figura del joven ecijano Antón Arjona.

Aunque no hay documentación que la fundamente históricamente, la visita a la Península Ibérica del Apóstol es considerada por los especialistas en la historia paulina como irrefutable. Igualmente, la estancia y la predicación en Écija del Santo vienen corroboradas por numerosos eruditos eclesiásticos (ROA, 1989: 134). En un momento dado, aunque pudiera parecer poco probable que alguien que venía a difundir el Cristianismo a un territorio tan lejano como la provincia romana de Hispania dentro del imperio visitara una ciudad de escaso interés por sus pequeñas dimensiones, como podia ser la Astigi romana, hay un dato que justifica plenamente esta visita. El acompañante del Santo en su visita a la Peninsula Ibérica, seguramente para ayudarle con las cuestiones idiomáticas, fue su discípulo Hieroteo (maestro a su vez de Dionisio de Aeropagita), que era oriundo de la ciudad astigitana. Otro dato que parece corroborar según los expertos la visita a la ciudad del Santo es la existencia en Écija de Silla Pontificia desde tiempos remotos'.

Según la tradición parece ser que el Santo prometió volver a la ciudad pero, debido a su encarcelamiento y martirio en Roma, esto no fue posible en vida, pero cumplió su promesa, si nos atenemos a su aparición ante el joven Antón Arjona. Exactamente, en la madrugada del 20 de febrero de 1436, según cuenta la tradición oral y escrita, San Pablo se apareció al joven Antón Arjona con el propósito de advertir a la ciudad que si seguia con los vicios y pecados que cometian contra Dios, éste haría caer sobre ella "penitencia grande". Para convencerlos unió los dedos de la mano del muchacho y le ordenó que organizara una procesión con las autoridades y el pueblo hasta el convento de San Pablo y Santo
Domingo. Delante de todos, obró el milagro de desunir los dedos del chaval. Existe un acta del milagro cuya copia más antigua que se conserva en el archivo municipal de la ciudad es de 1597 (OSTOS Y OSTOS, 1984: 54).

Esta relación de la ciudad astigitana con el Apóstol, que no se perdió de la memoria de sus habitantes ni en los siglos de la conquista musulmana, hizo que en 1573 se aprobara, por parte del Arzobispo Don Cristóbal de Rojas y Sandoval, el 25 de enero (festividad de la conversión de San Pablo) como fiesta obligatoria de la ciudad.

Será a partir de este momento cuando el culto a la figura del Santo y, por ende, la ejecución de imágenes del mismo, se haga de forma más amplia en la ciudad, aunque conocemos que antes de esa fecha ya se habian realizado representaciones escultóricas. Por documento de protocolos notariales sabemos que al pintor local Alonso de Orejuela se le encargaría en 1551 la realización de la policromía a la figura de San Pablo que era patrón de la Hermandad de Zapateros de la ciudad. El dorado y encarnado de la imagen se debería de hacer tomando como modelo el encarnado y estofado de la imagen de San Juan que estaba en la viga de la Iglesia de Santa Maria (HERNÁNDEZ DÍAZ; SANCHO CORBACHO; COLLANTES DE TERÁN, 1951: 310). Pero será justo después de la aprobación del 25 de enero como fiesta obligatoria de la ciudad, cuando la realización de representaciones del Santo en distintos formatos (relieves, pinturas o bultos redondos) se haga de forma más amplia. Es en este momento cuando se encuadra la ejecución de la escultura de San Pablo que nos ocupa.

En 1575 el Cabildo encarga una imagen del Apóstol para su procesión anual en la ciudad. Sobre el encargo y realización de esta imagen hay noticias que suscitan controversia. Por un lado, tenemos la trascripción, realizada por el que fue archivero de Écija, Manuel Ostos y Ostos, y publicada en 1915 en su libro San Pablo y la ciudad de Écija, del Acta del Cabildo de la ciudad celebrado el 3 de enero de 1575, en la que literalmente dice lo siguiente:

"que en aquel acto entró en la Sala capitular el R. Padre Prior del Convento de Santo Domingo fray Alberto de Escalera y manifestó

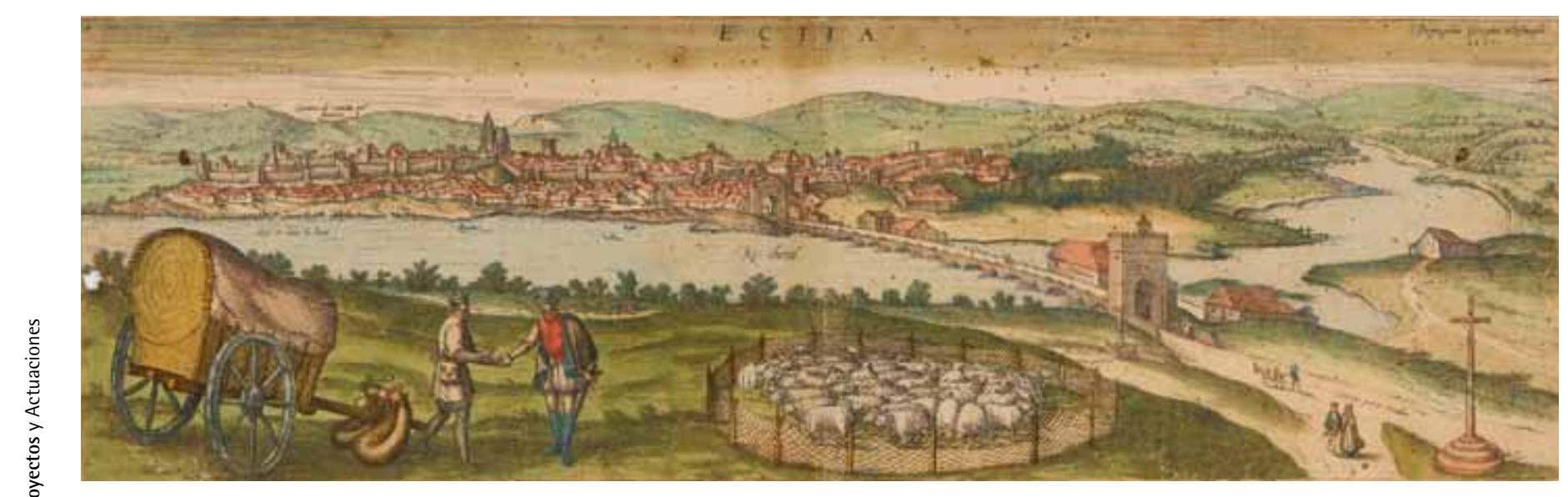

Grabado vista de Écija de 1567, de Joris Hoefnagle. Fuente: Colección Pablo Porres, publicado en Civitates Orbis Terrarum de George Braun. Foto: José Manuel Santos Madrid, IAPH 
que estaba terminada la imagen de San Pablo y que habia hecho, de su orden y por encargo que al dicho Prior confiriera el Cabildo, el maestro escultor ecijano Salvador Gómez de Navajas" (OSTOS Y OSTOS, 1984: 54).

Esta noticia es la que ha fundamentado la tradicional atribución de la imagen de San Pablo que nos ocupa a un desconocido escultor ecijano del que no se conoce ninguna otra obra ni referencia bibliográfica a excepción de la que citamos.

Por otro lado, el investigador Celestino López Martínez, en sus ingentes búsquedas documentales realizadas en los fondos del Archivo de Protocolos Notariales de Sevilla, encontró y publicó un documento que dice lo siguiente:

"Batista Bazquez e yo Gaspar del aguila escultores vzos de seuilla en san biceinte como pricipales e yo juan chacon pintor e juan de aguilar como sus fiadores otorgamos a los ylles señores concejo justicia e regimiento de la cibdad de ecija e decimos que por quanto nos batista bazquez y gaspar del aguila nos abemos obligado de hazer una imagen del bienaventurado apóstol san Pablo con quatro angeles dos a cada lado puesto en un lecho que se nombra pariguela y un tabernáculo donde la dha Imagen este que todo a de ser talla conforme a las muestras e dibuxos e condiciones su tenor de los quales es el siguiente.

Se a de hazer la figura del santo apóstol de madera de cedro que sea gueca por de dentro labrado en rredondo e con su montante de fierro - se a de hazer una pariguela e un tabernáculo de madera de borne de flandes ecetolas dos colunas que a de ser de pino de flandes - a de tener el tabernáculo dos baras y dos tercias de alto - la pariguela para llevar la imagen en procesión de borne de flandes y los angeles de cedro de tres quartas y media de alto con sus candeleros en las manos e guecos porque sean livianos - en precio de 170 ducados que se nos an de pagar luego la tercia parte dellos e que daremos fecha y acabada la dha imagen con todo lo demas dentro de dos meses en la ciudad de seuillla en las casas de nuestra morada" (LÓPEZ MARTÍNEZ, 1929: 105).

Es interesante hacer constatar que los datos que figuran en el contrato sobre materiales y ejecución de la obra ("Se a de hazer la figura del santo apóstol de madera de cedro que sea gueca por de dentro labrado en rredondo e con su montante de fiero") han resultado confirmados en los análisis realizados en la imagen durante su restauración.

Este contrato, que se realiza el 21 de agosto de 1574, fue publicado por el investigador en 1929 y hasta el momento no habia sido relacionado con la imagen que nos ocupa, ya que la bibliografía se habia limitado a repetir lo escrito por Ostos sin realizar un estudio crítico de la atribución. No será hasta la actualidad en la que los historiadores del arte astigitanos Gerardo Garcia y Jesús Porres, ante un estudio estilistico de la imagen y conociendo el docu-

\section{La imagen que nos ocupa \\ es la que desde 1575 ha \\ realizado la procesión}

mento publicado por López Martínez, deciden estudiar la posible vinculación de la escultura con el documento en cuestión.

Otros tres documentos apoyan esta nueva atribución. Por un lado, el 12 de noviembre de ese mismo año, se manda librar desde el Cabildo de la ciudad de Écija la cantidad de 150 ducados para pagar la hechura y su transporte desde Sevilla (HERNÁNDEZ DÍAZ; SANCHO CORBACHO; COLLANTES DE TERÁN, 1951: 310); el día 20 del mismo mes se volverán a librar 50 ducados a Alonso de Orejuela, pintor, por las gestiones y demás diligencias relativas a la hechura del San Pablo (HERNÁNDEZ DÍAZ; SANCHO CORBACHO; COLLANTES DE TERÁN, 1951: 310-311); y dos meses después, el 31 de enero, se librarán otros 30 ducados a cuenta del importe de la hechura y dorado de la misma (HERNÁNDEZ DÍAZ; SANCHO CORBACHO; COLLANTES DE TERÁN, 1951: 311). También es interesante la vinculación de este pintor astigitano, Alonso de Orejuela, con el encargo realizado a Gaspar del Águila en 1567 de un crucificado para el convento de San Agustín de Écija².

Pero será el estudio estilístico de la imagen el que nos lleve a corroborar de forma más firme su vinculación con los escultores manieristas Juan Bautista Vázquez EI Viejo y su discipulo Gaspar del Águila.

Considerando que la imagen que nos ocupa, sea de uno u otro de los autores citados, es la que desde 1575 ha realizado la procesión del dia 25 de enero al convento de San Pablo y Santo Domingo, vamos a concretar los cambios conocidos de ubicación a lo largo de su historia.

Nos consta, por la trascripción ya comentada que Manuel Ostos y Ostos realiza del acta del Cabildo celebrado por la corporación ecijana el 17 de enero de 1575, que al final de la misma figura un acta autorizada por el escribano Gerónimo Guzmán donde se describe y fija la forma en que había de salir la procesión y donde se concreta que la imagen del Santo quedaría depositada en las Casas del Cabildo, que en esas fechas se encontraban en los números ocho y diez actuales de la Plaza Mayor, que se llamaron en tiempos "del cabildo viejo" (OSTOS Y OSTOS, 1984: 54).

Cuando el Ayuntamiento, a mediados del siglo XIX, se traslada $\mathrm{Y}_{1}$ no existiendo en este nuevo espacio capilla para el culto -debido a que ya en esas fechas las instancias municipales se encuentran más separadas de los temas religiosos-, se decide que la imagen se instale en la parroquia de Santa Bárbara, por pertenecer la capilla del antiguo Cabildo a esa parroquia. Es en esta ubicación donde todavía se encuentra la imagen del Santo. 


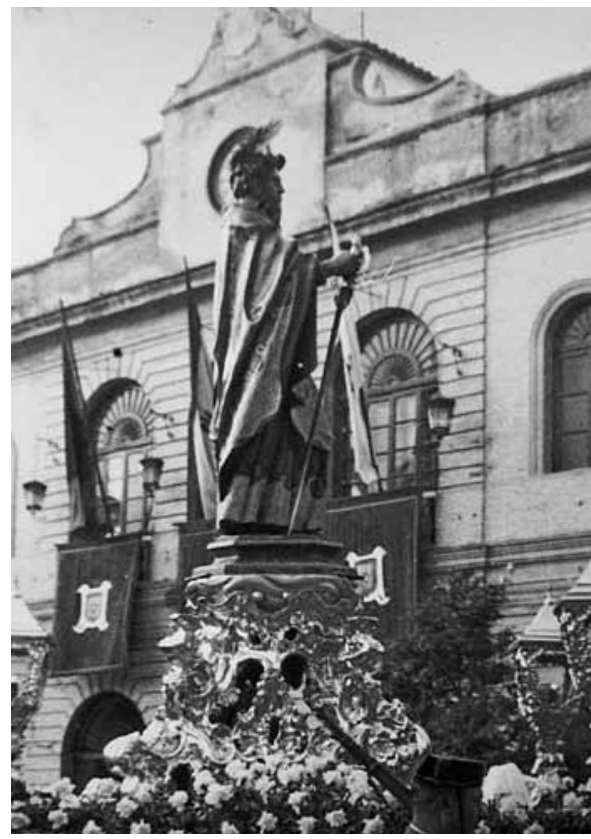

Procesión de San Pablo delante de la casa consistorial (circa 1950). Fuente: Archivo Parroquial Iglesia de Santa María (Écija)

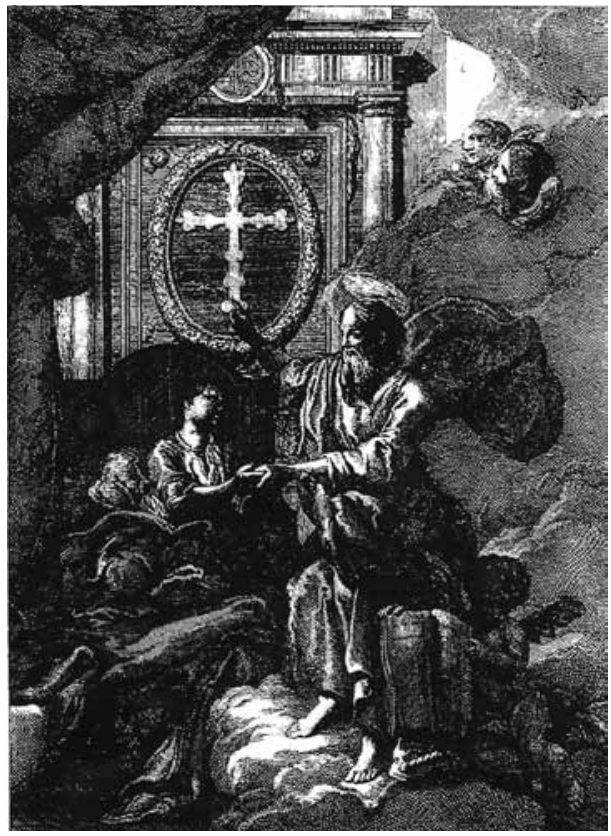

Grabado Milagro de San Pablo (anónimo, s. XVIII). Fuente: portada del libro San Pablo Apóstol y la Ciudad de Écija de Manuel Ostos y Ostos (Écija, 1915)

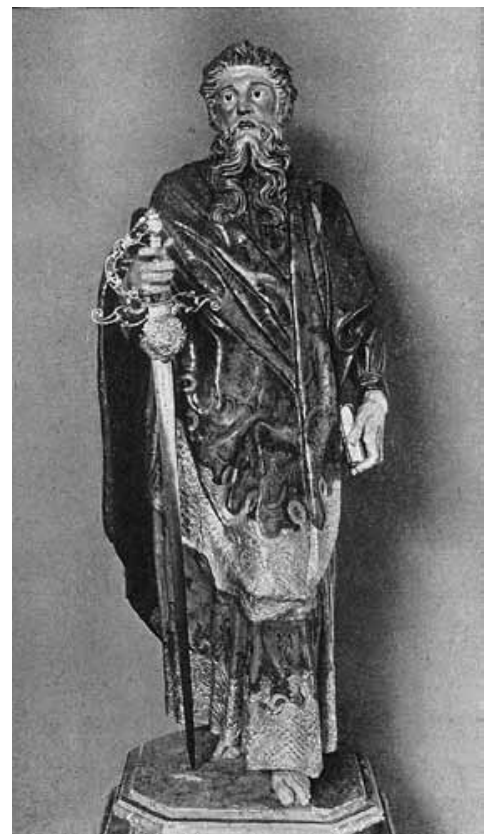

Imagen de San Pablo (circa 1950). Fuente: Archivo Fotográfico Laboratorio de Arte, Universidad de Sevilla

\section{SAN PABLO, VIDA E ICONOGRAFÍA}

La imagen que nos ocupa representa al Apóstol San Pablo, patrón canónico de la ciudad y el Cabildo de Écija. La iconografia del Santo, que es considerado como piedra fundamental de la Iglesia Universal, viene fundamentada por los aspectos de su curiosa vida.

Coincide en la figura de San Pablo una curiosa compilación de tres culturas que pudieron determinar, y que de hecho determinaron, su vida y su muerte. Por su origen étnico, San Pablo era judio; por su formación cultural, griego; y por su nacionalidad, romano.

Igualmente su vida podemos dividirla en tres periodos. El primero transcurre desde su nacimiento, entre el año tres y diez d. C. (periodo en el recibe una formación rabínica de manos de Gamaliel, que influyó en su visceral odio al Cristianismo), hasta su conversión. En esta época también recibió formación helenistica. Una segunda fase, de apostolado, comienza con su conversión: "Cuando estaba de camino, sucedió que, al acercarse a Dámasco, se vio de repente rodeado de una luz del cielo; y al caer a tierra, oyó una voz que decía: Saulo, Saulo, ¿por qué me persigues? El Contestó: ¿Quién eres Señor? Y El: Yo soy Jesús, a quien tu persigues. Levántate y entra en la ciudad, y se te diré lo que has de hacer" (Hechos de los Apóstoles 9, 3-7). Pasó, entonces, bruscamente del papel de perseguidor al de celador de la Cristiandad. A partir de la curación de la ceguera de Ananías comenzó su vida de misionero itinerante. La última etapa de su vida es la que pasa en Roma: en el año 60 embarcó hacia Roma, pero naufragó en la costa maltesa. Llegado a Roma permaneció presuntamente en ella hasta su muerte. Según Tertuliano habría padecido martirio en Roma al mismo tiempo que San Pedro, pero al ser ciudadano romano tuvo el privilegio de ser decapitado en lugar de crucificado.
San Pablo, en el arte primitivo, sólo tiene como atributo genérico un libro o rollo de pergamino. Su atributo personal, la espada, instrumento de su martirio, no apareció como parte de su emblema en la iconografia cristiana hasta el siglo XIII. Otra de las generalidades en la representación del apóstol de los gentiles es el de la incipiente calva o frente muy despejada y la barba abundante.

En nuestro caso no se cumplen todas las generalidades que venimos comentando. Aunque se le representa con su espada (en origen de madera y a partir de 1770 metálica y sobrepuesta), símbolo como ya hemos visto del privilegio como ciudadano romano en su martirio, y también con el libro que representa las Sagradas Escrituras, no presenta el rasgo caracteristico de la calva, ni se le representa, como habitualmente se suele hacer, como un hombre anciano, lo que se asimilaba en el pensamiento neoplatónico a la sabiduría. Quizás pudiera deberse este cambio en la representación a que San Pablo visitó la Península Ibérica aún joven.

\section{MORFOLOGÍA Y ESTÉTICA}

La imagen que nos ocupa es una escultura de bulto redondo, realizada en madera tallada y policromada. Que esté tallada con detalle en todo su perimetro nos indica que fue realizada para procesionar y no sólo como imagen de altar. Es algo más pequeña que el tamaño natural, $147 \mathrm{~cm}$ de altura, y se dispone de pie, en actitud de caminar, con el pie izquierdo adelantado sobre el derecho apoyando sobre una peana octogonal.

Su frontalidad nos indica que es una escultura manierista, al igual que la caída vertical de los paños, en los que hay ausencia de movimiento, como en el total de la representación, que sólo alcanza a ocupar el espacio con el adelantamiento del brazo derecho en 
el que porta la espada y el inicio de paso del pie contrario para compensar, lo que, en general, produce una sensación de pesadez y reposo muy cercana al manierismo romanista.

Es en la policromía donde podemos observar unas reminiscencias barrocas que corresponderian, seguramente, a la intervención acaecida en 1770, donde se repolicromaría y estofaría completamente la imagen.

Viste túnica y manto sobrepuesto con una decoración de hojarascas en tonos verdes, rojos y dorados. Tanto la túnica como el manto están ribeteados por una cenefa dorada realizada en yeso policromado en la que se reproduce en bajo relieve algo similar a un encaje o brocado con motivos de rocalla y una especie de rejilla adornada con pequeñas notas de color, verdes y rojas, a modo de piedras engarzadas en el tejido. La vuelta del manto presenta una policromía con una base dorada en la que se dibujan motivos vegetales en color blanquecino que se recubren al final con una "corla" o capa de barniz rojizo.

Porta la imagen un libro de las Sagradas Escrituras (en un principio se representaba con un pergamino plegado en forma de rollo) y una espada, simbolo de su martirio, que por lo que podemos suponer al conservarse el mango, en un principio fue de madera y en la actualidad presenta una metálica sobrepuesta que correspondería a la intervención sobre la imagen documentada en 1770. También a partir de esa fecha porta la imagen un relicario en forma de sol, colgado en su cuello, y una diadema con ráfagas.

La cabeza presenta una leve inclinación a la derecha, mostrando un rostro sereno con mirada perdida. Es de forma ovalada, con los pómulos y el surco naso-labial muy pronunciados. Las cejas rectas, poco pobladas, y la nariz de clara raigambre helenística. Todo ello está enmarcado por un pelo con el nacimiento bajo -algo poco habitual en las representaciones del Santo- y con una talla profunda de gubia formando mechones acaracolados muy semejantes a las esculturas del manierismo italiano. Del mismo tipo de talla está realizada la barba bífida en dos amplias madejas de pelo, de longitud y abundancia considerable.

Los ojos son de cristal, añadidos en un momento posterior al de la ejecución de la imagen, lo que puede quitar expresividad al rostro y también desvirtuar la expresión original. La zona de los párpados inferiores y superiores está ejecutada en yeso para tapar el horadado realizado para introducir los ojos de cristal.

Donde mejor podemos observar la calidad de la imagen es en la ejecución de manos y pies, con una talla virtuosa de gran realismo en la que se señalan tendones y venas.

\section{Transformaciones a través de la historia}

Debido a su uso como Patrón Oficial del Cabildo de la Ciudad de Écija, el simulacro ha sufrido en su historia material numerosas in- tervenciones que han modificado su imagen desde su concepción hasta la actualidad.

En 1611 tenemos noticia de que se pagaron ocho ducados a Pedro Freire, entallador, por aderezar el retablo, los ángeles, la imagen del Santo y la de Nuestra Señora (MARTíN PRADAS; CARRASCO GÓMEZ, 2007).

La segunda intervención fue realizada a principios del siglo XVIII y se encuentra recogida documentalmente en el Acta del Cabildo de la ciudad ecijana celebrada el 9 de febrero de 1714, donde se anotan los gastos producidos por el dorado y estofado de la escultura de San Pablo y su urna. Es interesante este dato que nos inclina a considerar que esta urna, entendida como paso procesional, fuera la realizada por Juan Bautista Vázquez y Gaspar del Águila, ya que en este contrato se habla de la realización de un paso, además de la escultura. Este apunte de las actas dice: "El señor D. Antonio de Montilla presentó a la ciudad una memoria de los gastos hechos en estofar y dorar la imagen del señor San Pablo y dorar su urna, que todo importó 1.100 reales y 17 maravedis de vellón que se librase la cantidad por el mayordomo" (HERNÁNDEZ DÍAZ; SANCHO CORBACHO; COLLANTES DE TERÁN, 1951: 302).

En 1770 es posible que se volviera a intervenir la imagen. Esta vez para la inclusión de la espada metálica, la diadema y el relicario, elementos que en la actualidad porta la imagen y que presentan el punzón del platero Gaitán. En la espada tiene la siguiente inscripción: "Enrique... en Alemania" por haber sido realizada por el alemán Enrique Coel. Y en la empuñadura de la espada figura la siguiente inscripción: "Año 1770".

Respecto a la espada sí podemos certificar la existencia de una anterior, realizada en madera, de la que se conserva la empuñadura,

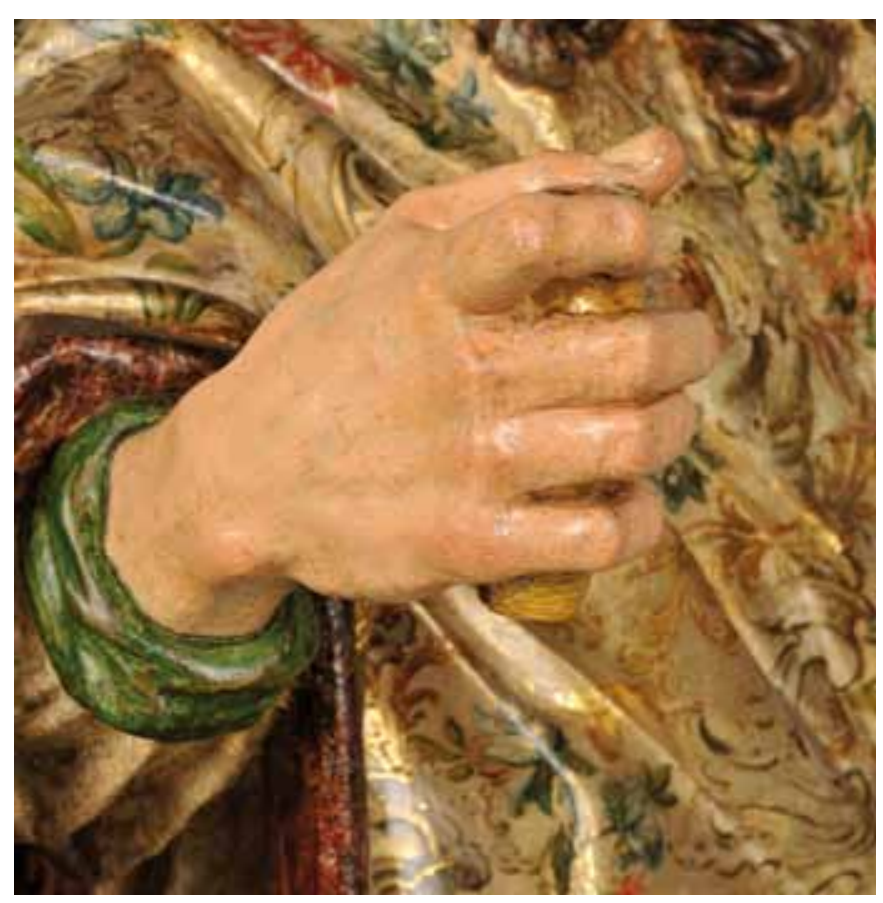

Detalle de la mano derecha de la imagen de San Pablo después de intervención en 2009. Foto: Eugenio Fernández Ruiz, IAPH 


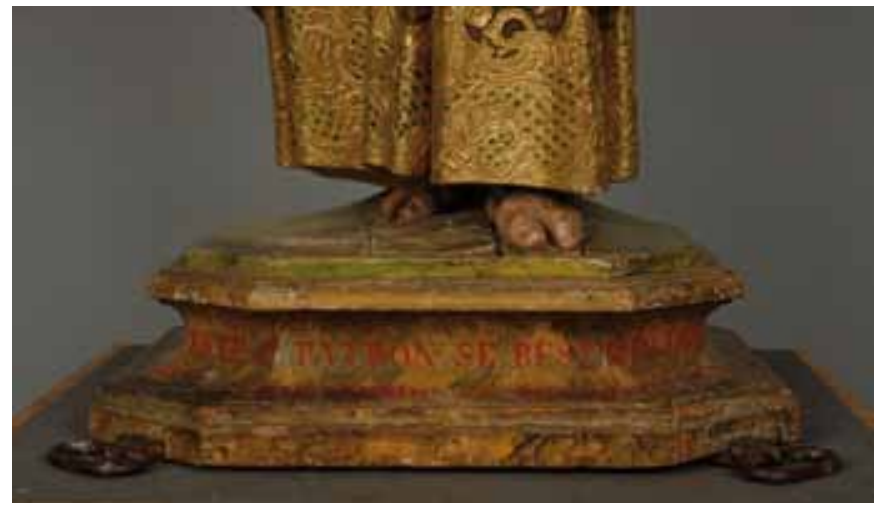

Peana de la imagen de San Pablo antes de intervención en 2009. Foto: Eugenio Fernández Ruiz, IAPH

que forma parte del trozo de madera en la que se talla la mano, por lo que no fue retirada sino que se utiliza como engarce de la espada metálica actual. El nimbo y el relicario son igualmente de dicha época. En el reverso del nimbo aparece la inscripción "Año de 1770".

A esta restauración también podria corresponder la decoración actual de la túnica y manto del Santo, ya que su estilo corresponde a esta segunda mitad del siglo XVIII, más que a la fecha de 1714 , en donde se "dora y estofa" de nuevo la imagen.

Pudiera ser en esta restauración cuando se le pudieron introducir los ojos de cristal que presenta en la actualidad la imagen, que no son originales, ya que no será hasta la segunda mitad del siglo XVII cuando se utilicen estos elementos, aunque también hay algunos datos, de correspondencia estratigráfica, que nos llevan a suponer que fuera en una intervención posterior. Originalmente la imagen tendría los ojos tallados en la madera y estaban policromados.

Por la observación y análisis de la imagen estos ojos se introdujeron por el rostro, concretamente por el hueco que ocupa el globo ocular entre las cejas y la parte superior de las mejillas, por lo que el modelado de los párpados superiores e inferiores debe corresponder igualmente a la misma restauración. Esto provoca que la imagen general del rostro no se corresponda con la original, lo que es un gran inconveniente para su comparación con otras imágenes del autor.

La última restauración de la que tenemos constancia documental se realiza en 1853, según consta en la leyenda pintada en el exterior de la peana de la imagen (realizada en esta fecha) y que dice: "Este Patrón se restauró con todo lujo en el año 1853 por cuenta del ilustrísimo ayuntamiento de esta ciudad siendo su presidente Juan Bautista Castillo y Bernuy, vizconde de Benaoján".

Sin constancia documental, sabemos por los análisis organolépticos y químicos efectuados a lo largo de la intervención en el IAPH que la imagen ha sufrido otras intervenciones puntuales, sobre todo en su policromía. Por ejemplo, la cenefa que rodea la túnica y el manto presentaba una capa de dorado de poca calidad que pertenecería a intervenciones del siglo XIX y aún del $X X, y$ que se ha eliminado para recuperar la subyacente que parece corresponder por estilo a la intervención documentada

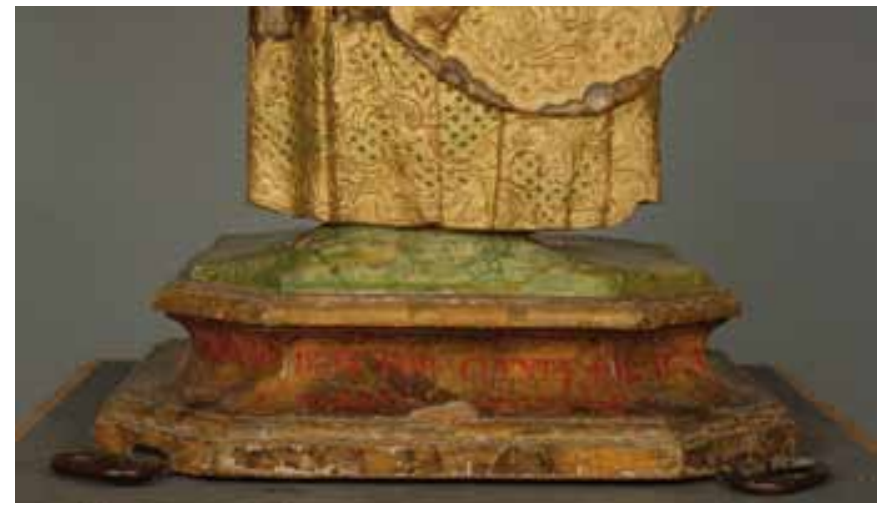

Detalle de la peana y la decoración de la túnica de la imagen de San Pablo en 2009. Foto: Eugenio Fernández Ruiz, IAPH

de 1770 . Esta cenefa dorada realizada en yeso correspondería a un añadido efectuado en esta restauración de 1770, por ser en esta época donde encontramos esta tipología de decoración de clara raigambre rococó.

En la zona de la vuelta del manto, también encontramos vestigios de otras intervenciones. Encima de la capa de barniz rojizo o "corla" que cubre la vuelta del manto, se encontraba una capa de pintura en tonos verdes que por sus características pudiera haber correspondido a intervenciones realizadas en los siglos XIX o XX y que ha sido eliminada en esta intervención para recuperar la policromía del siglo XVIII.

Tenemos conocimiento de que la imagen ha sido restaurada en el siglo pasado, sobre la década de los 60 por Guillermo Riego, quien hizo una limpieza general a la escultura, arreglando pequeños desperfectos de pérdidas de policromía y dándole un barniz para la protección de la obra.

\section{JUAN BAUTISTA VÁZOUEZ COMO AUTOR DE SAN PABLO, PATRÓN DE ÉCIJA}

Analizando estilistica y morfológicamente la representación de San Pablo que nos ocupa encontramos en ella una serie de características que nos hacen considerar como segura su vinculación con la que se contratara por el Cabildo ecijano y los escultores Juan Bautista Vázquez y su afamado discipulo Gaspar del Águila.

Es Vázquez un escultor en el que se conjuga perfectamente el realismo castellano con toques de manierismo italiano que serán el germen del naturalismo de la Escuela sevillana de escultura.

En la imagen de San Pablo encontramos estas caracteristicas y un virtuosismo en la talla que como hemos indicado nos inclinan a suponer que esta imagen fuera salida de su gubia o de la de su discipulo. Por un lado, la escultura presenta una talla realista y de gran virtuosismo en manos y pies, donde se señalan tendones y venas. Así mismo la talla del pelo, tanto en cabellera como en la barba, tiene influencia del manierismo italiano que encontramos en otras obras de Vázquez del que se supone visitó Italia y conoció las obras de los manieristas italianos. Esta talla de mechones aca- 


\section{JUAN BAUTISTA VÁZOUEZ, EL VIEJO, Y LA FORMACIÓN DE LA ESCUELA SEVILLANA DE ESCULTURA}

Aunque tradicionalmente se vino considerando a Juan Martínez Montañés como el fundador de la Escuela sevillana de escultura en los primeros años del siglo XVII, investigaciones efectuadas en la segunda mitad del siglo pasado han destacado que en la generación de escultores precedentes ya se observan rasgos comunes $y$ preferencias iconográficas que permiten hablar ya de una incipiente Escuela sevillana. Serán Isidro de Villoldo y, fundamentalmente, Juan Bautista Vázquez, EI Viejo, los que formulen las bases de esta escuela (BERNALES BALLESTEROS; GARCIA DE LA CONCHA DELGADO, 1986: 27).

Hacia 1553 recalará en Sevilla el escultor avulense Isidro de Villoldo, llamado para trabajar en el retablo mayor de la Cartuja. Hasta su llegada la escultura que se realizaba en la ciudad de mano normalmente extranjera tenía dos vertientes: por un lado, realizaciones del más puro renacimiento italiano y, por otro, otras de clara raigambre nórdica, tanto flamencas como germánicas. Será Villoldo, discipulo de Berruguete, el que presente una nueva forma de concebir la figura. Su obra en Sevilla es corta ya que muere en 1560 sin acabar el encargo del retablo para el que fue requerido otro escultor avulense, Juan Bautista Vázquez (BERNALES BALLESTEROS; GARCIA DE LA CONCHA DELGADO, 1986: 29).

Su llegada a la urbe coincide con el fallecimiento del entallador flamenco Roque de Balduque (1561) y de Isidro de Villoldo, convirtiéndose en uno de los escultores más solicitados de la antigua diócesis de Sevilla. Atraidos por una ciudad que gozaba tanto económica como social y culturalmente de un alto estatus, que tenía el monopolio del comercio de Indias desde 1503 con el establecimiento de la Casa de la Contratación, Sevilla será el destino elegido por numerosos artistas foráneos y extranjeros que acuden a la búsqueda de los innumerables encargos que, debido a la boyante economía, se originaban en esta ciudad (MORÓN DE CASTRO,1981: 166).

El escultor Juan Bautista Vázquez, El Viejo, o El Mayor, como lo distinguen los documentos de la época de su hijo homónimo y también escultor Juan Bautista Vázquez El Joven, representa quizás uno de los mejores exponentes de la imagineria renacentista de la segunda mitad del XVI en Sevilla y sin duda es el padre de una escuela enraizada en la ciudad hispalense, en la que destacaron artistas de gran talento como son Jerónimo Hernández, Gaspar del Águila o Miguel Adán por citar a algunos. Juan Bautista Vázquez fue un artista que se distinguió no sólo por sus labores como escultor sino también como retablista, pintor y grabador.

La obra de Vázquez en Sevilla es la que determina la formación de una escuela local, ambientada estilisticamente en el manierismo y con muchos vestigios clásicos (LÓPEZ, 2005: 46). La escultura sevillana, que giraba en torno a Roque de Balduque, va a sufrir una fuerte reacción con la presencia del maestro castellano. Los fondos clásicos en que se cimentaba el ambiente de la ciudad (su pasado romano) comenzaron a removerse ante las expresiones delicadas de raices idealistas de la escultura de Vázquez. En torno a él vinieron desde Ávila y Toledo artistas que conformaron el núcleo fundacional de la Escuela, como Juan de Oviedo El Viejo y Diego de Velasco, que ayudaron a la penetración de lo castellano en el ambiente andaluz (PALOMERO PÁRAMO, 1983: 168).

También estuvieron otros como Gaspar del Águila y Miguel Adán, quienes prosiguieron el camino que iniciaron Vázquez y Villoldo, aunque la definición de la escuela vino de manos de los seguidores más jóvenes de Vázquez, como su hijo Juan Bautista Vázquez El Mozo y en especial su discípulo Jerónimo Hernández. Vázquez se convertirá junto a su discipulo Hernández en abanderado de una nueva estética que se va a demandar en el último tercio del siglo.

Juan Bautista Vázquez, El Viejo, nació hacia 1525, al parecer en el pueblo de Pelayos, en la actual provincia de Salamanca. Su formación artística es, hasta el momento, un misterio. Algunos autores sostienen que realizó un viaje a Italia, donde habría ejercido como grabador, y que con posterioridad se habría establecido en Ávila, donde habría abierto un taller de escultura, si bien estos datos son un tanto inseguros.

Las primeras noticias documentadas de Vázquez lo sitúan trabajando en Toledo, en 1552, en la Puerta del Reloj de la catedral. Entre esta fecha y 1561 , año en que se establece en Sevilla, se abre una etapa en la que el maestro realiza encargos para una zona geográfica bastante amplia, que comprendería las actuales provincias de Guadalajara, Toledo, Madrid, Soria, Cáceres, Badajoz, e incluso Málaga y Granada. A esta época corresponden interesantes obras, como el retablo del Convento de la Concepción de Almonacid de Zorita, concertado en 1554, que se conserva sólo en parte y repartido entre Oropesa y Torrelaguna, el retablo de la parroquia de Mondéjar, iniciado antes de 1555 y destruido en 1936 durante la última contienda civil, o el retablo de la iglesia toledana de Santa María la Blanca, concertado en 1556 (ESTELLA MARCOS 1990: 6).

Su establecimiento en Sevilla supuso un gran cambio para la escultura que se estaba produciendo en la zona, ya que introdujo ideas bastante avanzadas. Permaneció en la ciudad y su entorno hasta su muerte, en 1589. Entre sus obras de esta época caben ser destacadas el modelado, realizado en 1568 , de la figura de la $\mathrm{Fe}$, más conocida como el Giraldillo, que sirve de remate a la Giralda, el Cristo de Burgos, en la sevillana parroquia de San Pedro, y el relieve de la Asunción, de la sala capitular de la catedral hispalense, terminado en 1580. Además en esta época hizo numerosas obras para distintas localidades andaluzas y extremeñas, a las que se pueden añadir otras destinadas a ser enviadas a América, donde se conservan varias tallas de su mano. Además de la escultura, sabemos que cultivó otros campos artísticos, como la pintura, el grabado, y posiblemente la arquitectura (BERNALES BALLESTEROS; HERNÁNDEZ DIAZ; MEGÍA NAVARRO, 1989: 162).

Respecto a su estilo podemos decir que está muy influido por el manierismo italiano, si bien algo alejado de las corrientes seguidoras de Miguel Ángel, tan del gusto de la España de aquel momento (romanismo), aunque encontramos características similares al florentino, incluso en esta obra, como sería la barba (compuesta de una manera similar al Moisés) o la monumentalidad que respira. Realiza figuras muy elegantes, de proporciones alargadas. Dispone por lo general los paños ceñidos a los cuerpos de sus figuras, en bandas estrechas que caen acentuando un movimiento en espiral. Los rostros de las figuras masculinas suelen denotar cierta magritud, mientras que los femeninos son excesivamente redondeados. 
racolados y la disposición de la barba son muy similares a la del Moisés de Miguel Ángel Buonarroti.

La imagen está muy en sintonía con otras obras realizadas por Bautista Vázquez en su etapa sevillana como pudiera ser la imagen de San Mateo, titular del retablo mayor de la Iglesia de San Mateo de Lucena realizada por Vázquez hacia 1575 (LÓPEZ MARTíNEZ, 1929: 107).

Consideramos que la escultura de San Pablo, patrón del Cabildo de la ciudad de Écija, tiene una calidad que excede en mucho a la que pudiera tener un escultor local como el desconocido Salvador Gómez de Navajas y que su calidad y similitud con otras obras de Vázquez hacen que la relacionemos con la contratada con este escultor y su discipulo, no sabiendo quién la ejecutaría en su totalidad, aunque la vemos muy cercana a la producción de Vázquez en esta época.

Posiblemente el Cabildo encargara al prior una imagen del Santo para que residiera en el convento $y$, al mismo tiempo, encargara para la procesión y la estancia en su sede del Ayuntamiento otra imagen a la capital. Este último encargo lo realizó a través del pintor local Alonso de Orejuela.

La imagen realizada por el escultor local Salvador Gómez de Navajas pudiera ser otra de las conservadas en la ciudad, ya que el corpus de obras paulinas de Écija es bastante extenso como pudimos comprobar en la exposición Iconografía de San Pablo en

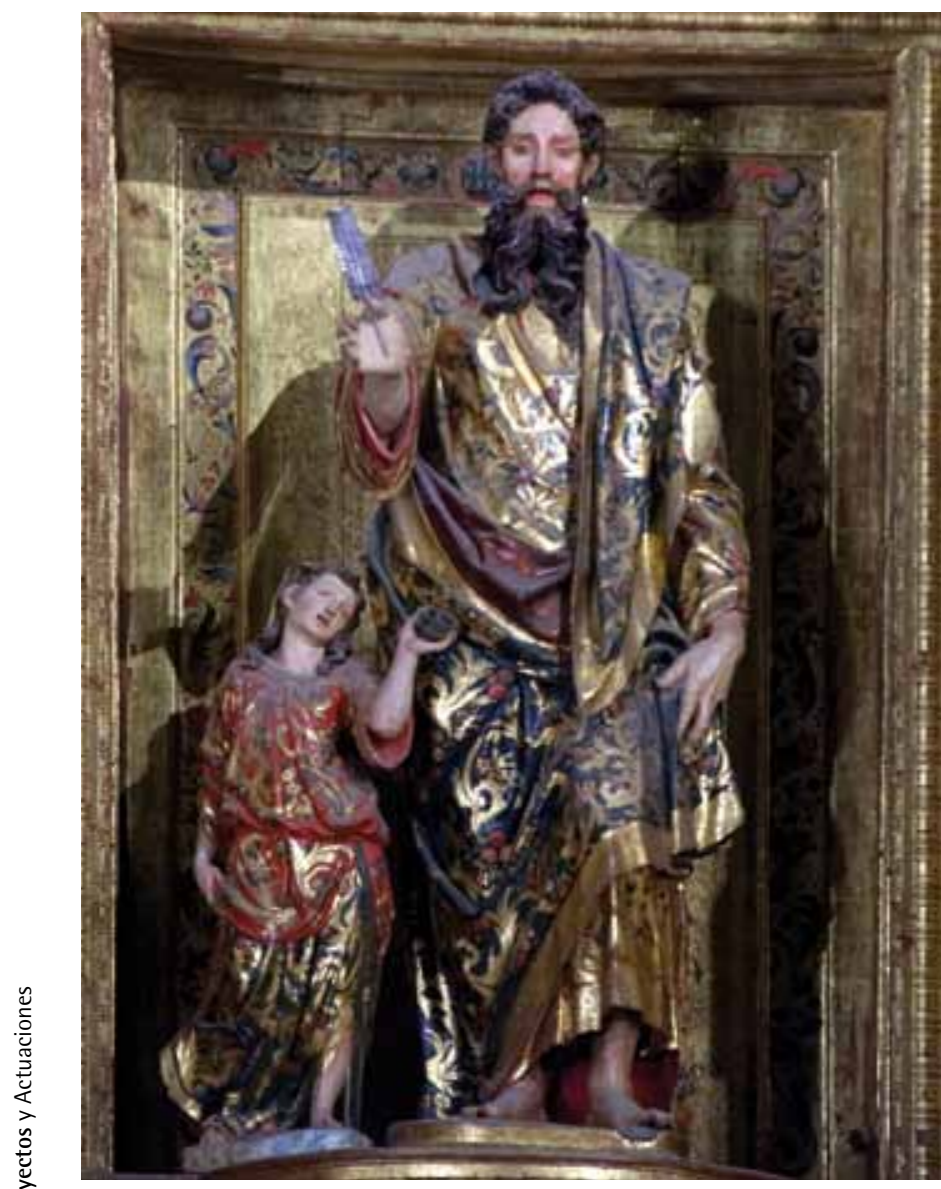

San Mateo en el retablo mayor de la Iglesia de San Mateo en Lucena (Córdoba) Foto: Francisco López Salamanca
Écija celebrada el año 2009 en la Iglesia de Santiago con motivo del año Santo Paulino.

Esta confusión debido a la proliferación de representaciones del Santo se recoge hasta en el Catálogo Monumental y Artístico de la provincia de Sevilla en el que se dan datos cambiados de dos imágenes, una ubicada en el Convento de Santo Domingo y otra en la Iglesia de Santa Bárbara, que es la que analizamos.

Por ello consideramos desestimar la atribución realizada por Ostos y Ostos al escultor local Salvador Gómez de Navajas y atribuirla a los escultores Juan Bautista Vázquez, El Viejo, y a su discipulo Gaspar del Águila. La vinculación de estos dos escultores con la ciudad astigitana es anterior al encargo del San Pablo. Ambos trabajaron conjuntamente para la ciudad de Écija en la realización de la labor escultórica del retablo de la Iglesia de Santa María en 1568 (HERNANDEZ DIAZ; SANCHO CORBACHO; COLLANTES DE TERÁN, 1951: 285) y Gaspar del Águila realizó, como ya hemos comentado anteriormente, en 1567, la imagen del Cristo de la Sangre de la iglesia de Santa Cruz. Es curioso que el documento del contrato de este crucificado se realizara con la misma persona que después se encargaria por el Cabildo para las gestiones de la contratación de la figura de San Pablo, el pintor local Alonso de Orejuela.

Es la calidad en la talla de la zona de manos y pies, amén de la ejecución de la cabellera y las zonas del rostro que no han sido tocadas con posterioridad, lo que nos inclina a considerar con más fundamento la hipótesis de que esta imagen se corresponda con la contratada por el Cabildo con Vázquez El Viejo y Gaspar del Águila, más que con la que hiciera el escultor local Salvador Gómez de Navajas, del que, dado su desconocimiento general, suponemos que se trataria de un escultor con menores capacidades técnicas y estéticas que los anteriormente citados.

\section{INTERVENCIÓN EN LA IMAGEN}

La intervención que se realizó ha actuado desde dos perspectivas diferentes: un tratamiento de indole conservativo, con objeto de eliminar los daños que presentaba; y la aplicación de los tratamientos de restauración que requiere la obra de cara a su presentación estética teniendo en cuenta el carácter devocional que presenta.

\section{Estudios previos}

El estado de la obra ha requerido la realización de una serie de estudios previos que aporten la información necesaria para la realización de la intervención.

Por un lado, el estudio científico se ha basado en: la toma radiográfica frontal y lateral de la obra; un barrido fotográfico general con iluminación ultravioleta y otro con natural; el estudio estratigráfico con lupa binocular. También se procedió a un estudio 
analítico que consistió en un examen preliminar con el microscopio estereoscópico, la observación al microscopio óptico con luz reflejada de la sección transversal (estratigrafía), con el fin de determinar la secuencia de estratos así como su espesor, y el estudio al microscopio electrónico de barrido (SEM) y microanálisis elemental mediante energía dispersiva de Rayos X (EDX) de las estratigrafias, para la determinación de la composición elemental de los pigmentos y cargas.

Se extrajeron dos muestras de policromía de la imagen para su estudio estratigráfico (SPA-1 Carnación, zona del párpado del ojo derecho y SPA-2 Carnación, mano derecha del Santo).

También se extrajo una muestra de madera de la peana de la imagen para su estudio biológico y se concluyó que era Pinus sylvestris (MENGUIANO CHAPARRO; SAMEÑO PUERTO, 2009: 3), siendo una especie diferente de la que encontramos en el resto de la escultura.

\section{Tratamiento}

El tratamiento que se ha llevado a cabo ha sido una intervención de tipo integral y devocional, con objeto de neutralizar las patologias que presenta y reintegrando cromática y volumétricamente aquellas partes que lo necesiten. La descripción del tratamiento no sigue una secuencia temporal real y se adapta a la estructura de la memoria: en primer lugar el soporte, posteriormente la preparación y en último lugar el estrato pictórico.

\section{A nivel de soporte:}

- Revisión de todos los ensambles y consolidación de aquellos que lo necesiten, para conseguir la estabilidad necesaria. Se han consolidado las fendas en la zona de la espalda, así como las fendas y pérdidas de soporte que tenía en otras zonas.

- Colocación de pasta madera en zonas donde lo ha necesitado, como en las pequeñas grietas para una mejor estabilidad del soporte. - Introducción de pequeñas chirlatas de madera en zonas donde ha sido posible, bien por el recorrido regular de las separaciones o porque había espacio suficiente para la introducción de éstas (como por ejemplo en la parte superior de la peana). Reconstrucción de algunas piezas como el dedo meñique de la mano derecha, con pequeñas piezas de madera y pasta "araldit", tallándolo hasta darle la forma real.

- Cuando ha sido posible, se han eliminado los clavos de forja y puntillas, porque ya no cumplen su función de ensamble y además porque aportan oxidación al entorno circundante. En algunos casos fue imposible su extracción (sobre todo por los daños circundantes que esto provoca) o por la adhesión tan fuerte que tenian; de modo que se ha procedido a rebajar la parte saliente o introducirla con un botador asi como neutralizarla con productos quimicos y protegerla con un barniz especial. Los dos grandes tornillos existentes en la peana y que atravesaban la figura taladrándole los pies se ha considerado que era mejor dejarlos debido al daño estructural que podia acarrear su eliminación.

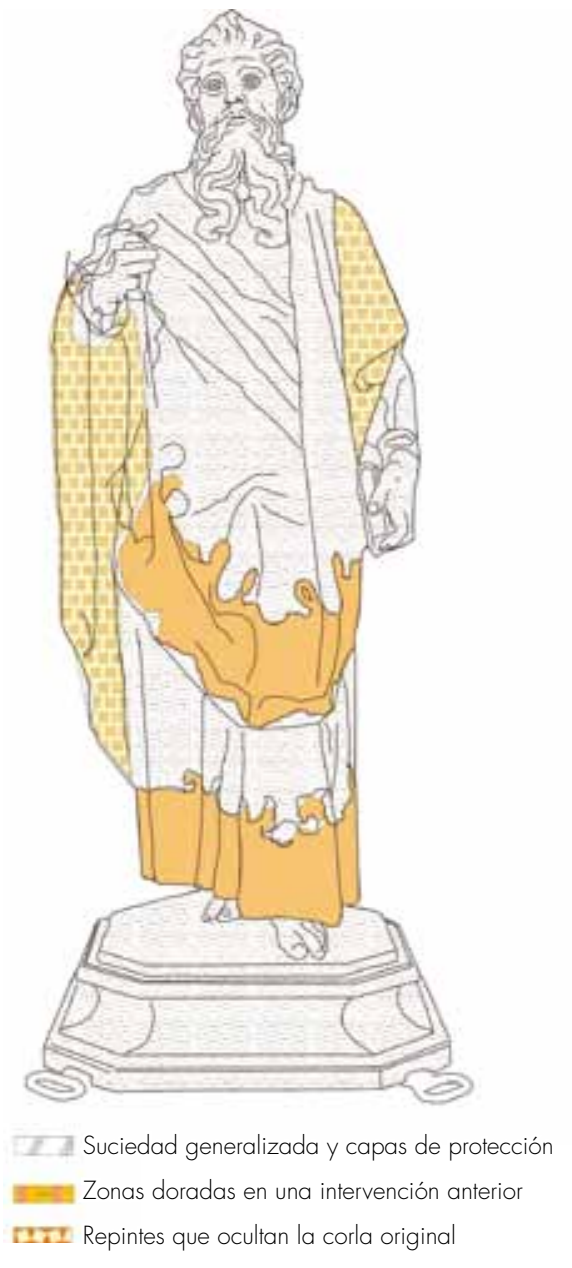

Gráfico de los daños en la imagen de San Pablo (2009). Gráfico: Jesús Porres Benavides, IAPH

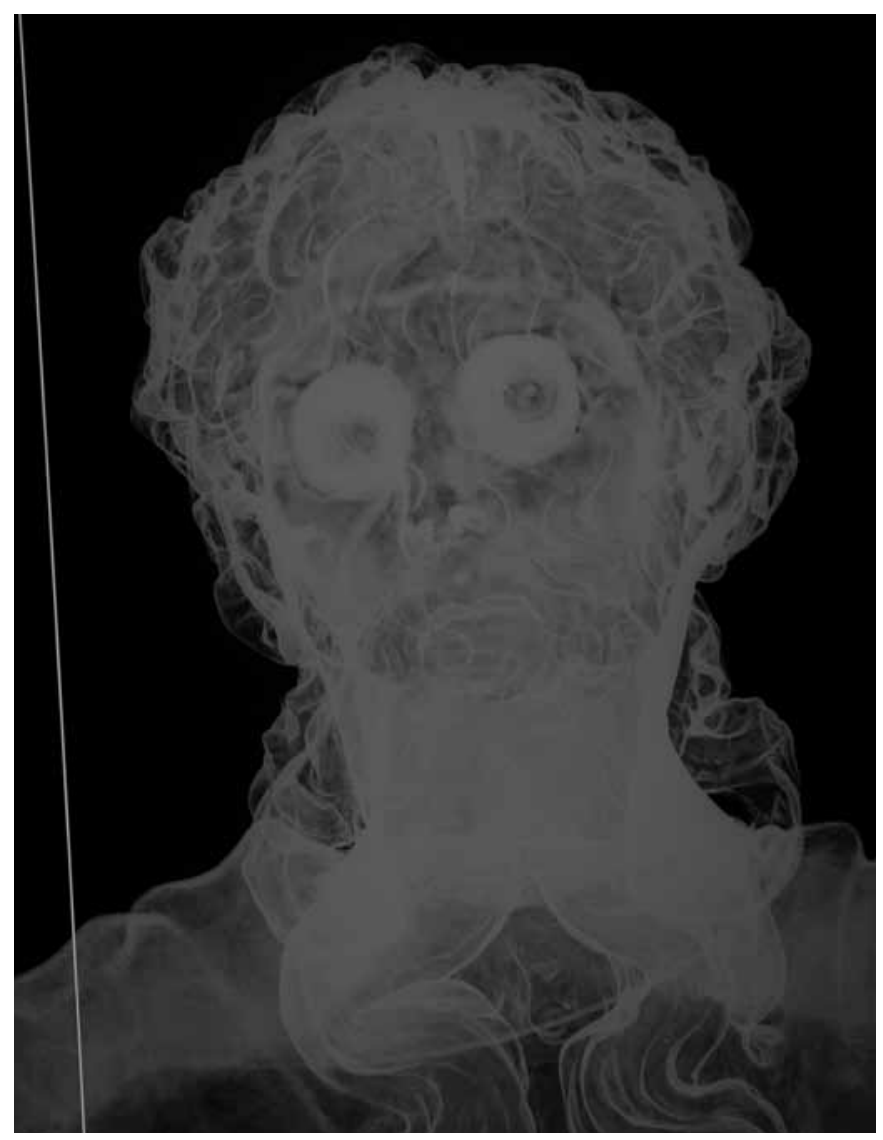

Radiografía detalle cabeza de la imagen de San Pablo (2009). Radiografía: Eugenio Fernández Ruiz, IAPH 


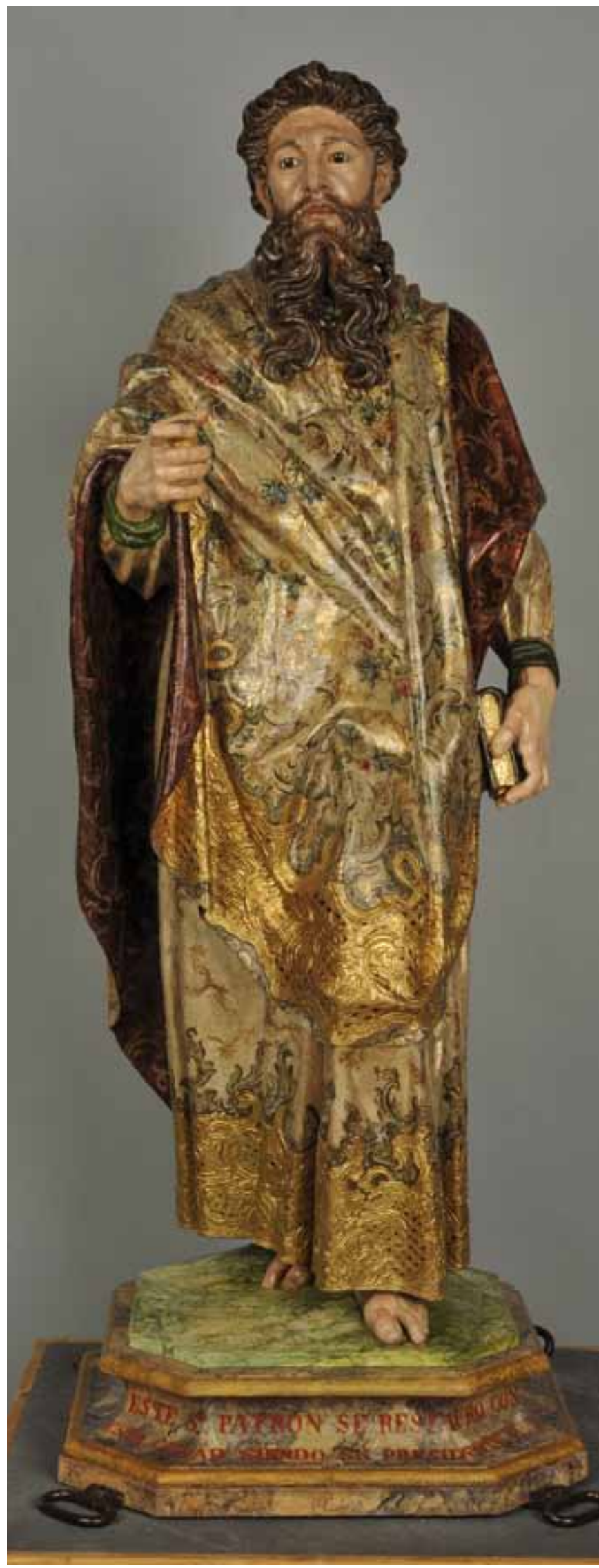

San Pablo. Foto: Eugenio Fernández Ruiz, IAPH
A nivel de preparación:

- Fijación de las áreas con riesgo de desprendimiento de los estratos policromos y, en las zonas donde se ha perdido adhesión, una fijación de la preparación mediante adhesivos. En su mayor parte se ha utilizado coleta aplicada con calor y presión, y puntualmente Primal B52. Como se comentó en el apartado anterior, el cuarteado pronunciado que presentaba la imagen en zonas de la encarnadura se ha minimizado, con las operaciones de fijación con calor, presión y adhesivo.

- Tras los estudios organolépticos y analíticos correspondientes, se han eliminado algunas preparaciones que perjudicaban a la obra y que ocultaban la preparación original o simplemente se consideró necesario su eliminación (como en las zonas estucadas nuevamente en la anterior intervención).

- Se han estucado las lagunas y pequeñas grietas con sulfato cálcico y cola. Se han enrasado y lijado convenientemente hasta dejar una superficie adecuada.

A nivel del estrato pictórico:

- Se ha realizado una limpieza general de la obra, de tipo mecánico, para eliminar el polvo y la suciedad acumulados. Posteriormente se hicieron los test de solubilidad para determinar el disolvente o mezcla de ellos adecuados para la remoción y eliminación de los barnices, redorados o repintes alterados y desbordantes.

- Posteriormente se llevó a cabo la limpieza de la superficies, retirando los barnices y suciedad en la imagen; y en las encarnaduras, se retiró el repinte que las ocultaba al igual que en el pelo. Mayoritariamente se ha utilizado disolventes por medio de hisopos de algodón, que funcionaban correctamente en las zonas doradas y de temple, aunque puntualmente se han utilizado gasas impregnadas de disolventes en algunas zonas pues hinchaba los depósitos acumulados en los intersticios del punzonado y facilitaba su eliminación.

- En zonas como la peana, la limpieza presentó algunos problemas debidos al pigmento rojo existente en la leyenda que la recorre, que era muy débil y se desgastaba con facilidad, por lo que se tuvo que realizar una limpieza quimica con hisopos muy pequeños para controlar mejor ésta.

- En las manos y pies se han eliminado los repintes que ocultaban parcialmente la policromía que se quería recuperar. Se han alternado procesos mecánicos con químicos para su eliminación, auxiliados con la lámpara de lupa binocular.

- Se ha eliminado el dorado de la última intervención que cubría las orlas decorativas en relieve, devolviendo el suyo original y las corlas, pues ocultaba la capa polícroma original, y se consideró, por criterio visual y diferencial, eliminarlo.

- También se procedió a eliminar la corla de una intervención posterior en la vuelta del manto, para dejar visible la original, con la consiguiente complicación técnica de eliminación de óleos y dorados sobre corla; más dificultad supuso la eliminación de unas decoraciones vegetales que estaban encima de la corla original, que debido a su dureza se debieron de eliminar de manera mecánica.

- Se han reintegrado las lagunas con técnicas acuosas reversibles utilizando una técnica de "rigatino" reversible y diferenciable. 
Después se procedió a proteger la superficie con un barniz líquido aplicado a brocha. Posteriormente se ultimó la reintegración cromática mediante colores al barniz (comúnmente denominadas "restauro").

- Paralelamente al proceso de tratamiento en la escultura, se realizó el estudio fotográfico de todos los procesos que se consideraron oportunos documentar y, por último, se recogió toda la información obtenida de la obra y de la intervención efectuada en una memoria de intervención.

La imagen de San Pablo no se ha mantenido a lo largo de su historia como fue concebida. Las obras de arte están expuestas a múltiples intervenciones máxime si se trata de las que tienen carácter devocional. En el caso que nos ocupa, las intervenciones, con los cambios que conllevan, configuran las caracteristicas técnicas y estéticas de la obra, que es lo que hace que una obra de arte sea única. Con esta perspectiva el tratamiento realizado ha intentado en todo momento respetar y conservar estos aspectos.

\section{Notas}

1 La ciudad de San Pablo, en Revista Ecclesia, 26 de marzo de 2009 <http://www. revistaecclesia.com/index.php?option=com_content $\&$ task=view\&id=9340\&ltemid $=65>$ (consulta: 10/09/10).

2 Reseña Histórica en la web de la Hermandad de la Sangre de Écija <http://lasangre-ecija.blogspot.com/2008/10/resea-historica.html> (consulta: 10/09/10).

\section{Bibliografía}

ALBARDONEDO FREIRE, A. (1994) Recuperadas las Santas Justa y Rufina de Juan Bautista Vázquez el viejo. ABC (martes, 18-10-1994). Sevilla, p. 60 BERNALES BALLESTEROS, J.; GARCÍA DE LA CONCHA DELGADO, F. (1986) Imagineros andaluces de los siglos de Oro. Sevilla: Biblioteca de Cultura Andaluza, 1986

BERNALES BALLESTEROS, J.; HERNÁNDEZ DÍAZ, J.; MEGÍA NAVARRO, M. (1989) El Arte del Renacimiento. Colección Historia del Arte en Andalucía, v. V. Sevilla: Ediciones Gever, 1989, $1^{\text {a }}$ ed.

CEÁN BERMúDEZ, J. A. (2001) Diccionario histórico de los más ilustres profesores de las Bellas Artes en España. Madrid: Ediciones ISTMO, 2001 ESTELLA MARCOS, M. (1990) Juan Bautista Vázquez el Viejo en Castilla y América. Madrid: Consejo Superior de Investigaciones Científicas, 1990 GARCíA ROSELL, C. (2005) Juan Bautista Vázquez, el Viejo. En AA. W. Del Gólgota a la Resurrección. Sevilla: Ediciones Tartessos, 2005, Tomo IV, 1a ed. HERNÁNDEZ DÍAZ, J. Artes y artistas del Renacimiento en Sevilla. En W. AA. Documentos para la Historia del Arte en Andalucía. 1ª ed. Sevilla: Universidad Laboratorio del Arte, 1933, t. VI

HERNÁNDEZ DÍAZ, J.; SANCHO CORBACHO, A.; COLLANTES DE TERÁN,

F. (1951) Catálogo arqueológico y artístico de la provincia de Sevilla. Sevilla: Diputación de Sevilla, 1951, v. III

LÓPEZ MARTíNEZ, C. (1929) Desde Jerónimo Hernández hasta Martínez

Montañés. Sevilla, 1929

LÓPEZ, F. J. (2005) Juan Bautista "el Viejo" y su posible autoría del Cristo del Amor. Revista Llamador. $1^{\text {a }}$ ed. Cuaresma 2005. Boletín de la hermandad de los Dolores del Viso del Alcor

MARTÍN PRADAS, A.; CARRASCO GÓMEZ, I. (2007) Nuestra Señora del Valle y San Pablo: Sacralización de espacios urbanos y rurales en el término municipal de Écija. Actas de las V jornadas de protección del patrimonio Histórico de Écija. Écija: Asociación de Amigos de Ecija, 2007, pp. 173-224
MENGUIANO CHAPARRO, V.; SAMEÑO PUERTO, M. (2009) Informe de identificación de materiales de la imagen de San Pablo de Écija del Centro de Análisis del IAPH. Sevilla, 2009

MIURA ANDRADES, J. M. (1992) Fundaciones religiosas y milagros en la ciudad de Écija. Écija: Gráficas Sol, 1992

MORÓN DE CASTRO, M. F. (1981) Análisis histórico estilístico del retablo mayor de la Catedral de Sevilla. En AA. W. El Retablo Mayor de la Catedral de Sevilla. Sevilla: Monte de Piedad de Sevilla, v. 1, 1981, pp. 121-172

MURO OREJÓN, A. (1932) Artífices sevillanos en los siglos XVI y XVII. En W. AA. Documentos para la Historia del Arte en Andalucía. Sevilla: Universidad, Laboratorio del Arte, 1932, t. IV OSTOS Y OSTOS, M. (1984) San Pablo Apóstol y la ciudad de Écija. Écija: Asociación de amigos de Écija, 1984

PALOMERO PÁRAMO, J. M. (1983) El retablo sevillano del Renacimiento. Análisis y evolución (1560-1629). Sevilla: Diputación, 1983

PORRES BENAVIDES, J. (2009) La imagen de San Pablo de Écija, algunas pistas sobre su autoria. En Actas del la VII Jornadas de Protección del Patrimonio Histórico de Écija. Écija: Asociación de Amigos de Écija, 2009, pp. 233-244 PRAT, F. San Pablo. En The Catholic Encyclopedia. New York: Robert Appleton Company, 1911, V.

ROA, M. DE (1989) Écija, sus santos y su antigüedad eclesiástica y seglar. Écija: Imprenta Juan de los Reyes, 1989

VILLANUEVA ROMERO, E.; RUBIO FAURE, C. (2002) Informe Diagnóstico de la imagen de San Pablo de Écija. Instituto Andaluz de Patrimonio Histórico (IAPH). Sevilla, 2002

\section{FICHA TÉCNICA}

Restauración de la imagen de San Pablo, patrón de Écija (Juan Bautista Vázquez y Gaspar del Águila, 1575)

Román Fernández-Baca Casares

Director del IAPH

Lorenzo Pérez del Campo

Jefe del Centro de Intervención del IAPH

\section{Equipo técnico del IAPH}

Jesús Porres Benavides, restaurador. Taller de Escultura,

Centro de Intervención

Carmen García Rosell, historiadora del arte. Departamento de Investigación, Centro de Intervención

Lourdes Martín García, química. Departamento de Análisis,

Centro de Intervención

Víctor Menguiano Chaparro, Marta Sameño Puerto,

biólogos. Departamento de Análisis, Centro de Intervención

Eugenio Fernández Ruiz, fotógrafo. Laboratorio de Medios Físicos de Examen, Centro de Intervención

Plazo de ejecución

Julio 2009-enero 2010 